\title{
Empirical Investigation of Barriers and Driving Forces for Efficient Energy Management Practices in Non-Energy-Intensive Manufacturing Industries of Bangladesh
}

\author{
A. S. M. Monjurul Hasan ${ }^{1, *}$, Rakib Hossain ${ }^{1}$, Rashedul Amin Tuhin ${ }^{2}$, Taiyeb Hasan Sakib ${ }^{1}$ and \\ Patrik Thollander ${ }^{3,4, *}$ \\ 1 Department of Electrical and Electronic Engineering, Bangladesh Army International University of Science \\ and Technology, Cumilla 3501, Bangladesh; rakib@baiust.edu.bd (R.H.); taiyeb_hasan@baiust.edu.bd (T.H.S.) \\ 2 Department of Computer Science and Engineering, East West University, Dhaka 1215, Bangladesh; \\ mcctuhin@ewubd.edu \\ 3 Division of Energy Systems, Department of Management and Engineering, Linköping University, \\ SE-581 83 Linköping, Sweden \\ 4 Department of Building, Energy and Environment Engineering, University of Gävle, 80176 Gävle, Sweden \\ * Correspondence: monjurul@baiust.edu.bd (A.S.M.M.H.); patrik.thollander@liu.se (P.T.)
}

Received: 2 April 2019; Accepted: 8 May 2019; Published: 10 May 2019

\begin{abstract}
Improved energy efficiency is being considered as one of the significant challenges to mitigating climate change all over the world. While developed countries have already adopted energy management and auditing practices to improve energy efficiency, the developing countries lag far behind. There are a limited number of studies which have been conducted in the context of developing countries, which mostly revolve around highly energy-intensive sectors. This study looks into the existence and importance of the challenges to and motivating forces for the adoption of energy management practices in Bangladesh, a developing country, focusing on the non-energy-intensive manufacturing industries. Conducted as a multiple case study, the results indicate the existence of several barriers towards adopting and implementing the management of energy practices in the non-energy-intensive industries of Bangladesh, where among them, "other preferences for capital venture" and "inadequate capital expenditure" are the most dominant. This study also identified a number of driving forces that can accelerate the acceptance of energy efficiency practices, such as the demands from the owner, loans, subsidies, and a lowered cost-benefit ratio. Findings of this study could assist the concerned stakeholders to develop beneficial policies and a proper regulatory framework for the non-energy-intensive industries of developing countries like Bangladesh.
\end{abstract}

Keywords: energy management; industrial energy efficiency; energy policy; sustainability

\section{Introduction}

Bangladesh has shown promising stability, having a population of over 160 million with the increase of industrialization over the last 20 years [1,2]. The energy management practices to improve energy efficiency has become one of the primary concerns for the government (e.g., reducing $\mathrm{CO}_{2}$ in the atmosphere) and for private investors, in order to achieve maximum return on the capital invested [3]. As industrialization is at its peak, a developing country like Bangladesh is bound to conduct the necessary research for adequate energy management and improvement in energy efficiency to minimize the use of energy so as to decelerate the greatest environmental impacts originating from the use of energy [4]. 
The use of fossil fuel is one of the key contributors of global warming. Global warming has been playing a key role in implementing policy instruments which may increase the energy prices and demand for industrial energy efficiency $[5,6]$. Industrial energy efficiency deals with the prominent threat of the environment-that is, global warming [7,8]; hence, there is a modern-day need which researchers need to investigate. Studies have been carried out at several European Union (EU) countries for improved industrial energy efficiency, such an example being [9]. However, the gap in the implementation of energy efficiency practices in developing countries contributes significantly to the barriers [10]. Given the fact of a significant rise in price over the last decade, it is very difficult for a developing country like Bangladesh to have a sophisticated energy management enticement in the industrial sector [11].

The government has taken many steps to meet the country's high electricity demand due to the distinct rise in numbers of industries, including having electricity imported from neighboring countries such as India, the establishment of several thermal power plants, and the expansion of renewable energy technologies, especially the solar home system. The total installed capacity of power plants as per the Bangladesh Power Development Board (BPDB) in April 2019 was 18,675 MW, in which $52.88 \%$ is fueled by gas, $23.87 \%$ is fueled by HFO (Heavy Fuel Oil), $12.89 \%$ is covered by HSD (High Speed Diesel), $2.51 \%$ by coal, $1.3 \%$ by hydro power, and $6.55 \%$ by electricity imported from other countries [12]. In the years 2009-10, natural gas consumption by the industry sector was $16.9 \%$, which dictated the industry sector being in the second position from the point of view of natural gas consumption [12]. The government's fuel diversification program was one of many significant approaches taken so as to provide opportunities both for public and private investors to harvest more renewable energy approaches to meet the rising energy demands due to industrialization [12]. Several energy efficiency measures have been taken, such as the installation of reflective glasses where their reflective coating reflects light in commercial buildings for passive cooling, security lighting in municipal establishments powered by solar energy and installation of irrigation pumps powered by solar energy replacing diesel/electric pumps, installation of solar dryers instead of electric/gas dryers, and the installation of solar water heaters instead of electric/gas heaters among the consumers of distribution zones of BPDB [12]. Distribution zones of BPDB have also been established for smooth electricity distribution systems at different parts of the country. This reduces the cost of laterals, feeders, transmission equipment, and substations. In order to protect the environment, which is one of the primary concerns of energy efficiency, BPDB planning methodologies have been modified, giving principal consideration to the quantity of emitted stack gas and cooling water from thermal plants [12]. However, more energy efficiency and management studies are required to meet the growing industrial economy, where the growth can be visualized from the expected growth of the steel industry alone by $15 \%$ [11]. As there are more than 400 companies in the market providing different demands for non-energy-intensive and energy intensive industries, a proper study of energy efficiency is a prominent field of study in order to achieve a satisfactory return from the point of view of private investors and to protect the environment, provided that the energy demands have been met.

Increased efficiency of energy use in the industrial sector of Bangladesh will lead to significant cost savings, given the fact that there was a $1990 \mathrm{MW}$ demand for electrical power by the industrial sector, which is approximately $40 \%$ of the total electricity consumed in that year [13]. Private sectors dominate the investments in industrial technology [14]. Due to inadequate policies and effective pricing, the country's energy sector has been facing difficulties in attracting private investments [15]. In this study, companies with energy costs that are lower than $2 \%$ of the turnover are considered non-energy-intensive industries.

The aim of this paper is to study the hurdles and motivations (often considered as "barriers" and "driving forces") for efficient energy management practices in the non-energy-intensive industries of Bangladesh in the manufacturing sector. The goal of this study leads to the following research questions: 
1. Drivers for implementing energy efficiency practices in low-energy-using industries of Bangladesh.

2. Major barriers for implementing energy management measures.

3. Energy efficiency potential in low-energy-intensive industries of Bangladesh.

4. Existing long-term energy management strategies.

Similar studies had been made for Sweden, Ghana, and a number of European industries $[5,9,10,16]$. However, there are a limited number of studies which have been conducted in the context of developing countries like Bangladesh. Energy efficiency in Bangladesh industries is an unexplored area, particularly within the non-energy-intensive industry area, where studies about the barriers and drivers of energy efficiency measures are scarce. This paper will summon the exploration of the presence of various challenges towards energy efficiency practices in the low-energy-intensive industries in Bangladesh, and the implication of these barriers. Investigations of barriers to and drivers for energy efficiency are absolutely critical in recognizing the instruments of how energy management practices are embraced. This study represents barriers to and drivers for implementing energy management practices in the non-energy-intensive industrial sector in Bangladesh.

The formation of the remaining part of this paper is as follows: Section 2 presents information about the energy management system, the methodology section is discussed in Section 3, the findings of this study are presented in Section 4, and Section 5 incorporates the discussion of this study.

\section{Energy Management System}

The energy management system is the process of adopting some productive strategies to triumph over the hurdles to energy efficiency [17-19]. Energy management systems have the potential to save up to $40 \%$ of total energy [11,20]. It is the procedure of observing, directing, and preserving energy in a building, organization, or distribution system [21]. It incorporates the process of selecting from a set of sources that are able to generate energy which will deliver energy to a set of loads by reducing losses and costs $[9,22]$. In the last 20 years, its importance has been increased in industries as a support function [22,23]. It is required to address the modifications that are mandatory for electrical utilities to improve infrastructures and functions to surpass imminent challenges. These modifications include enhanced situational consciousness and visualizations, reliability, network automation, and security [24]. The foremost step of strategic energy management is to set out how energy will be managed by the organization. This includes an initial plan of action of the tasks, which involves understanding the organization's present situation and establishing the management framework [25]. After establishment of the framework, the detection and execution of energy efficient schemes should be addressed [26]. Without active participation from the top management, an energy plan or energy strategy may be designed and launched in vain. Top management support is crucial for the successful deployment of the plan, as well as the benefits and costs associated with implementing it.

Patronage from the upper management for an internal program of energy management is also pivotal [9]. One next stage could be the implementation of things such as an Energy Management System (EMS), Supervisory Control And Data Acquisition (SCADA), the generation management system (GMS), and a distribution management system (DMS), which is required for supervising, controlling, managing, generating, and distributing energy [22]. These systems employ the collection of data and storing them in order to analyze hundreds of thousands of data points in networks, and then modeling and simulating the data in the networks. After that, one aims to pinpoint faults and to pre-empt outages, and to finally possess in trading markets $[27,28]$. Any type of attack, such as intrusion, alteration, falsification of data, and interruption of communication may hamper the automation of energy management. To ensure the security of the automation system and technological infrastructure, general security goals that could be identified may differ $[29,30]$. 


\section{Energy Efficiency Programs in Bangladesh}

The Sustainable and Renewable Energy Development Authority (SREDA), a government organization of Bangladesh, has been the main stakeholder, along with several Non-Government Organizations (NGOs) to implement energy-efficiency-related programs at the industrial sector of Bangladesh [31]. The organizations have initiated several schemes, such as energy management, energy efficiency standard setting and labelling, and financial incentives. at the industries. The main features of the energy management scheme by SREDA are ensuring that there is a dedicated energy manager and that an energy audit is periodically done at the industries [32]. However, the focus of energy management programs has mainly been on energy intensive industries (e.g., textiles, steel, pharmaceuticals) [32]. Figure 1 represents the initiatives taken by SREDA to implement energy efficient technologies at the industries.

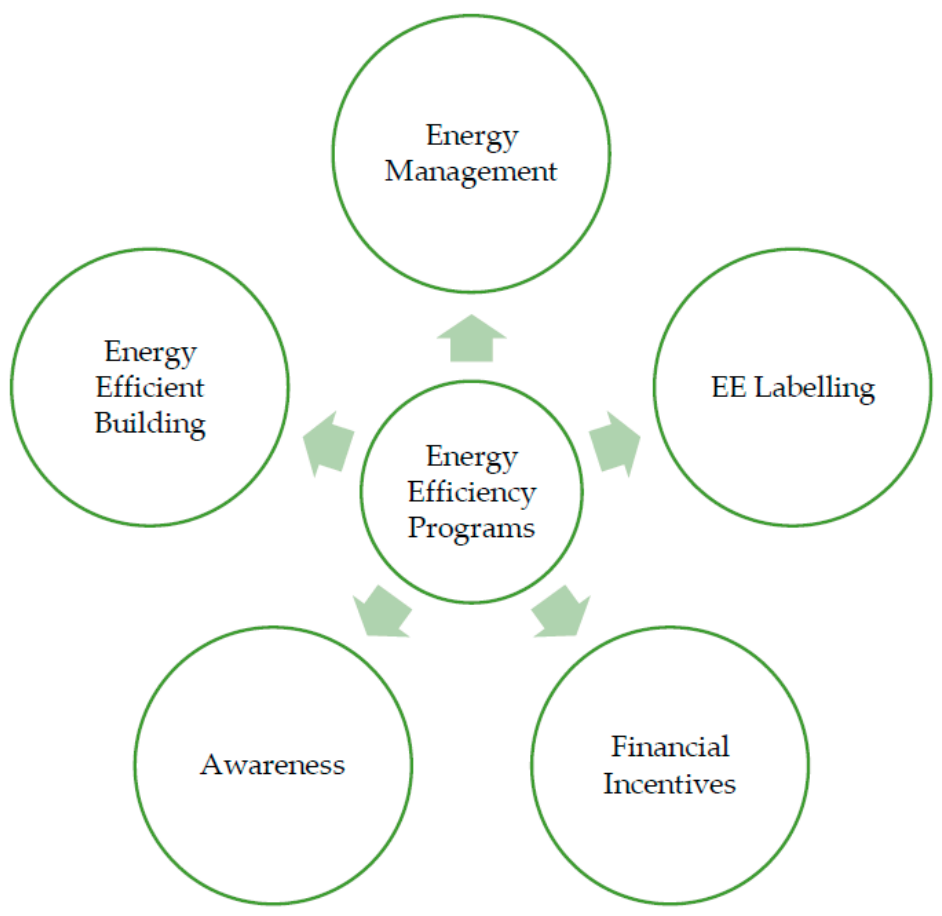

Figure 1. Energy efficiency programs/initiatives taken by the Sustainable and Renewable Energy Development Authority (SREDA), Bangladesh [32].

Energy related issues are acquainted mainly by national policy papers [33,34]. Electrical energy generation has been the key feature at the energy policies of Bangladesh. The "National Energy Policy, 2005", "The National Sustainable Development Strategy, 2013", and "Intended Nationally Determined Contributions, 2015" emphasized energy generation guidelines and plans. The "Energy Efficiency and Conservation Master Plan up to 2030" is one of the recent policies that incorporates mainly energy efficiency-related issues. The key feature of this policy is the implementation of Demand Side Management (DSM), maintaining proper pricing schemes. In addition, financial incentives, preferential taxation, and subsidies are proposed in this policy; however, it is yet to be approved by the Government of Bangladesh.

\section{Methodology}

The aim of this study was to contribute to an overall improvement in the energy management research field by investigating the present practices of energy management in low energy-intensive industries at Bangladesh, considering the fact that the previous works that covered industrial implementation of energy efficiency is limited in South Asia. Moreover, the investigation in Bangladesh 
has been incorporated to shed light on adopting cost-effective energy efficient technologies. The research uses a case study approach, considering its nature $[35,36]$. Semi-structured interview questions were used for data collection. Similar types of questionnaires were used previously for the low energy-intensive industries in Sweden [5]. The questionnaire used in the study is attached as a supplementary file.

In this study, the selection of the industries was on a random basis, based on the registered list of small and medium-sized industries in Bangladesh [37]. Initial communications were done over the phone, and possible interview times were scheduled. After getting the approval from the respondent's end, the questionnaire was sent to them electronically. All the respondents held the position of being responsible for the energy-related issues in their companies, and were ranked as "Factory Manager". The respondents had more than ten years of experience in their relevant field. As the data was collected through a set of questions, it hence provided a general perception of the person being interviewed on behalf of the industry concerned. The validity of the perception of the respondents is significant, considering their extensive experience in the relevant field. At a later phase, the data was cross-checked over the phone again.

A summary is presented in Table 1 about the data collection method of the study.

Table 1. Summary of the data collection method.

\begin{tabular}{cc}
\hline Topic & Comment \\
\hline Number of industries questionnaire was sent to & 35 \\
\hline Number of respondents & 8 \\
\hline Rate of response & $23 \%$ \\
\hline Type of companies & 8 \\
\hline Total questions in the questionnaire & 64 \\
\hline Interviewee selection criterion & Person mainly responsible for energy-related issues \\
\hline Designation of the respondents & $\begin{array}{c}\text { Factory manager } \\
\text { Interview }\end{array}$ \\
\hline & $\begin{array}{c}\text { Questionnaire was sent electronically to the } \\
\text { respondents, and results were validated in the later } \\
\text { phase }\end{array}$ \\
\hline
\end{tabular}

Closed-format questions were asked, except the energy-efficiency potential segment in this study. The company profile was asked at the beginning, which included turnover, energy use, and workforce. The authors collected the data from eight types of industries, and the number of total participating industries were 35 in this study. Primary data was collected in Fall 2018, and more results were incorporated at a later phase. A summary of the studied industries is presented in Table 2.

Table 2. Overview of the studied industries.

\begin{tabular}{|c|c|c|c|c|c|c|c|c|}
\hline Industry & 1 & 2 & 3 & 4 & 5 & 6 & 7 & 8 \\
\hline Facilities are outsourced? & No & No & Yes & No & No & No & No & No \\
\hline $\begin{array}{l}\text { Energy Service Companies } \\
\text { (ESCOs) }\end{array}$ & No & No & No & No & No & No & No & No \\
\hline Type of industry & Printing & Candles & Bakery & Pen & Batteries & Furniture & Trucks & Transformer \\
\hline
\end{tabular}

The questionnaire covers barriers and drivers towards energy efficiency and its potential in regard to energy management and energy service companies. The first section of the questionnaire focused on technological matters, challenges in terms of finance and the market, as well as managerial and human factors. The drivers towards energy efficiency are emphasized in the second section of the questionnaire. The latter part was concerned with the efficiency potentiality of the industries. 
The "energy management" section was concerned with policy-related issues, the institution and its information systems, consciousness, and investment-feasible technologies. The last section was comprised of energy service companies. In this study, participants ranked the barriers and drivers (based on their perception) on a Likert scale, " 1 " being "Not important at all" to " 5 " being "Very important". The cumulative findings of this study were adjusted in the latter phase of this study. However, as only the arithmetic figures were considered of the responses, perception differences were not included in the study.

\section{Results}

\subsection{Barriers to Energy Efficiency}

Our study found that the significant barriers to energy efficiency in non-energy-intensive industries of Bangladesh were "Inadequate capital expenditure", followed by "Other preferences for capital venture". Six manufacturing industries identified these as the most significant barriers. "Time limitation or other significant work", "Inadequate support from preeminent administration", "Unpredictability nature of energy parameters (prices, slow rate of return)", and "Inadequate financial policy" were chosen by five out of eight manufacturing industries that participated. The other significant drivers identified were "Inadequate financial incentives", "Inadequate technical experts", "Insufficient attention from government", "Lack of staff consciousness", "Inadequate information about allotment of energy expenditure", "Ambiguity about latent costs", "Inadequate technical cost-effective measures", and "Inadequate information about energy efficiency options". The less significant barriers identified from this study were "Complication in inter-divisional collaboration", "Limited influence on energy management", and "Complex syndical issues", which were marked by four respondents as important. Figure 2 represents the elaborated outcomes of the study.

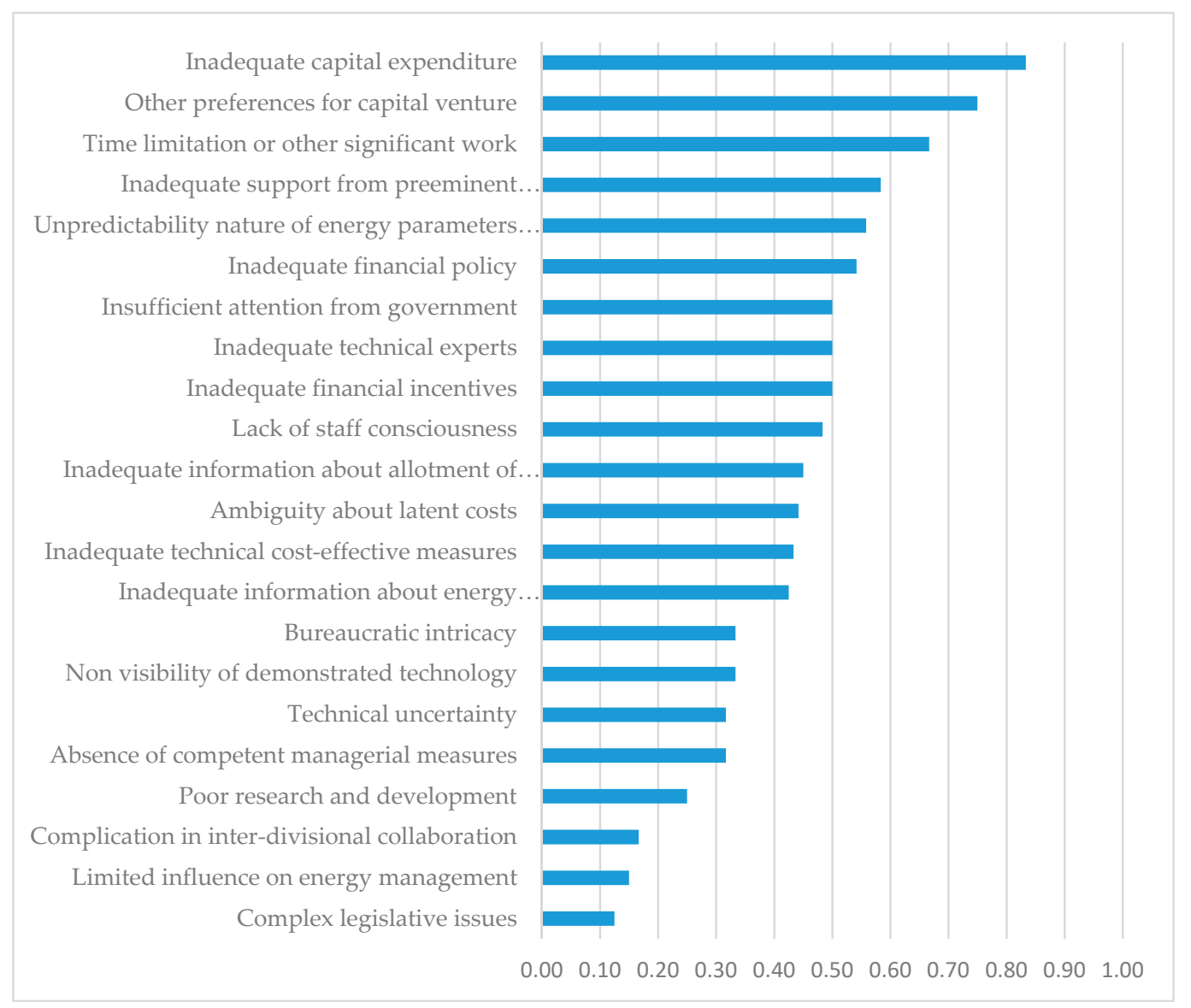

Figure 2. The perceived barriers to energy efficiency by the respondents. 


\subsection{Drivers to Energy Efficiency}

"Owner's requirement" was perceived as the highest ranked driver for energy efficiency. Besides this, the other prominent drivers were "Expense minimization due to lower energy consumption", followed by "Assurance from preeminent management" and "Risk of high energy prices in future". However, "Favorable loans for efficient energy financing" and "Agreements with tax dispensation" were also identified as important drivers, followed by "Rules and regulations". The lowest ranked drivers were "Certification in sustainable system", "Organizational involvement in information and support", and "Acquaintances within the energy sector". Figure 3 presents the visual outcomes of the study.

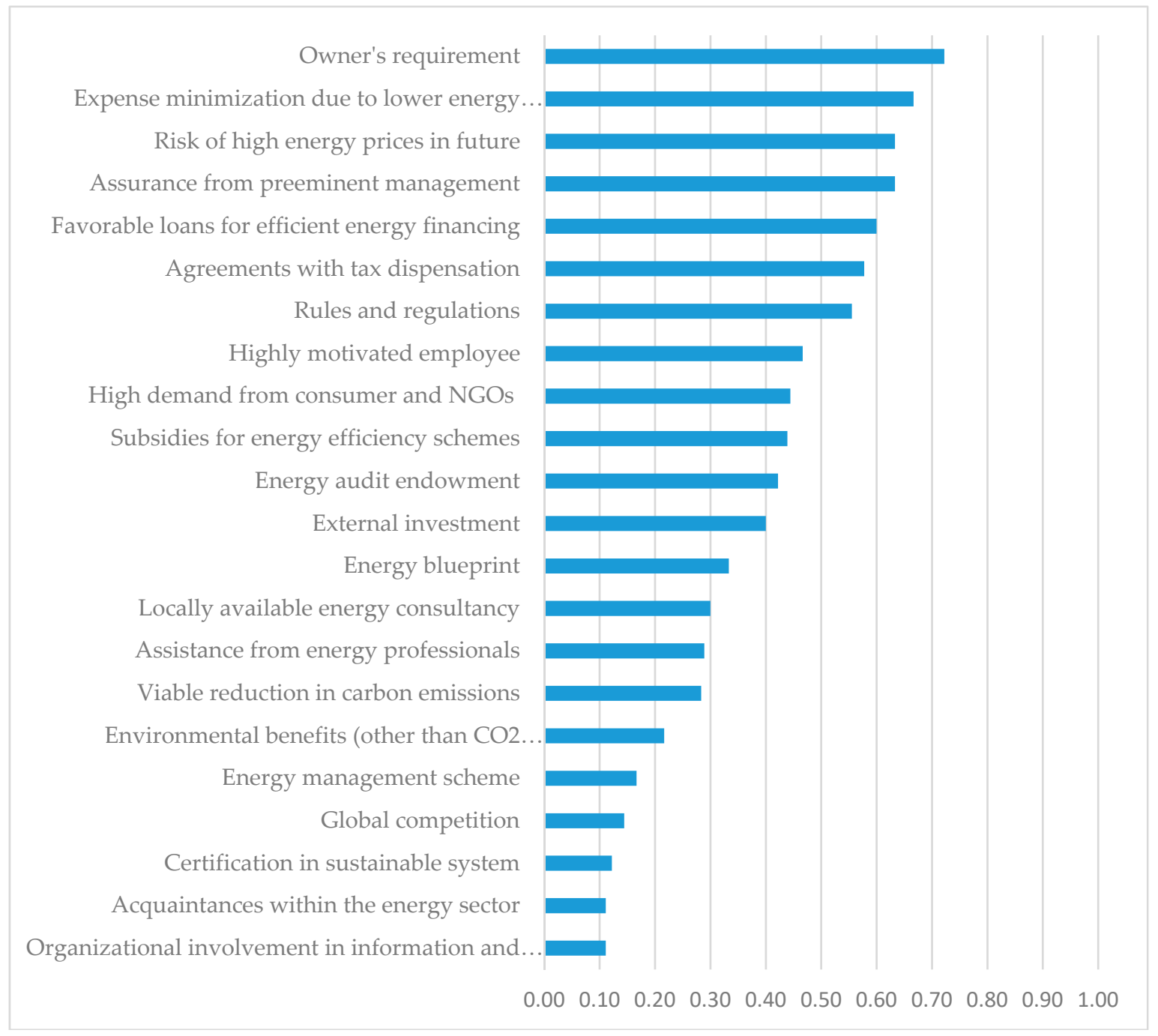

Figure 3. The perceived drivers for energy efficiency by the respondents.

\subsection{Energy Efficiency Potential}

In this study, the participants were asked about the energy efficiency potentials. The first question was about the overall energy reduction of energy use, considering the cost-effective energy-efficient technologies which were available. The study divulged that 2-3\% of energy could be salvaged with present technical options. Afterwards, the respondents were asked about the improvements in energy efficiency through energy management practices. Energy usage could be optimized by $3-4 \%$ according to a majority of the respondents through energy management measures. The participants were given a set of questionnaires considering a framework to assess alternatives for augmented performances in energy efficiency. All the participants gave an apical score in this inquiry. In addition, the participants 
recommended considering a framework point of view to assess, where the alternatives for energy efficiency were censorious.

\subsection{Energy Management}

Organization, policy, information system, awareness, and investment were the five classifications taken into account while evaluating the energy management measure matrix [24,26]. The considered categories are acquainted with other means of energy management practices. Figure 4 presents the energy management practices at low energy-intensive industries of Bangladesh. It is observed that there is an extensive potential for changes in each classification of the energy management matrix. The factors to improve were "Investment", "Policy", "Awareness", and "Information system". The stakeholders concerned should be taught about energy management practices considering sustainability and production.

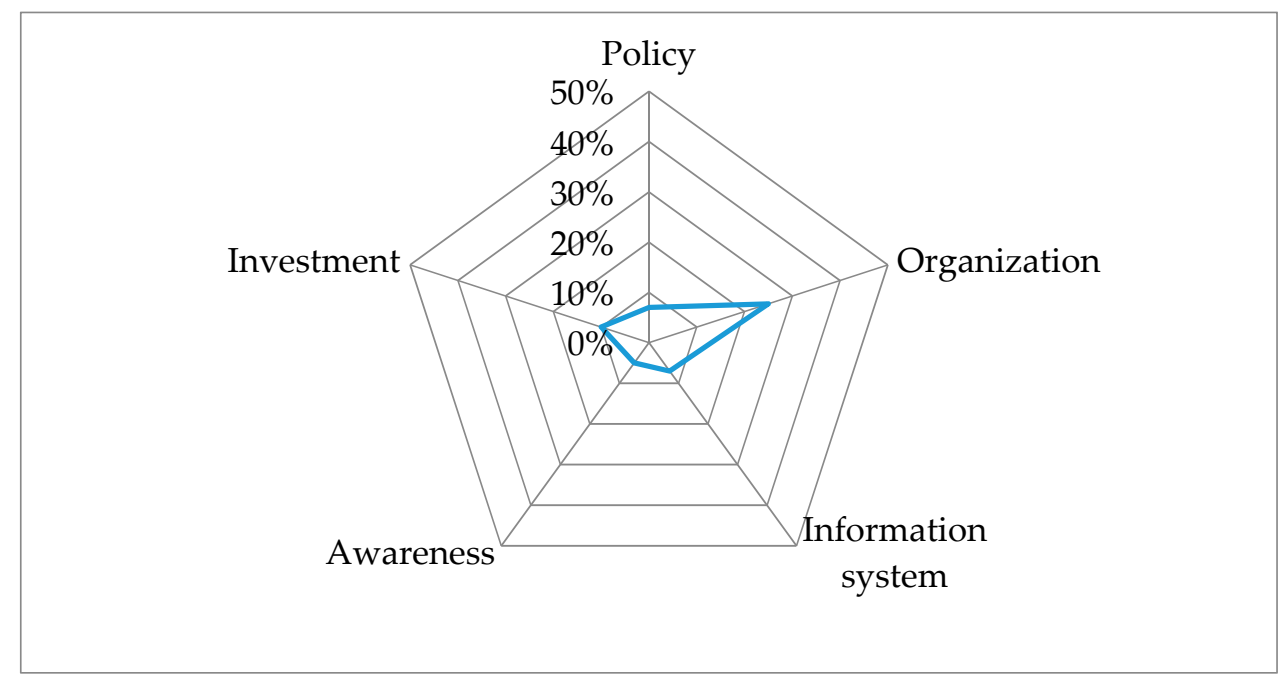

Figure 4. Assessment of energy matrix in non-intensive energy industries of Bangladesh.

\subsection{Energy Service Companies (ESCOs)}

The academic literature has significantly proposed energy services as a promising instrument used to conquer the challenges for energy efficiency in non-energy-intensive organizations [38,39]. Consultation with ESCOs is a route for industries to outsource parts or most of the energy management practices [40]. ESCOs have the advantage of utilizing organizational insights on different occasions related to energy $[38,41]$. This study found that the concept of an energy service company was novel to low energy-intensive industries of Bangladesh, though energy service company are considered as a substantial actor in terms of sustainability, as well as energy efficiency. As the concerned stakeholders of the industries studied were not acquainted with the idea of ESCO, they tended to utilize their internal experts only. Therefore, the market for energy service companies for the country's low energy-intensive industries has been devoid till now. The barriers to taking services from ESCOs were studied in this study. The study found that "Insufficient information regarding ESCO" was the most significant barrier, followed by "Inadequate stakeholders" and "Shortage of trained professionals in energy management". The elaborated outcomes of the subjects on various barriers are represented in Figure 5. 
Insufficient information regarding ESCO

Inadequate stakeholders

Absence of regulated measures for energy parameters

Shortage of trained professionals in energy management

Excessive service fees

Lack of credibility

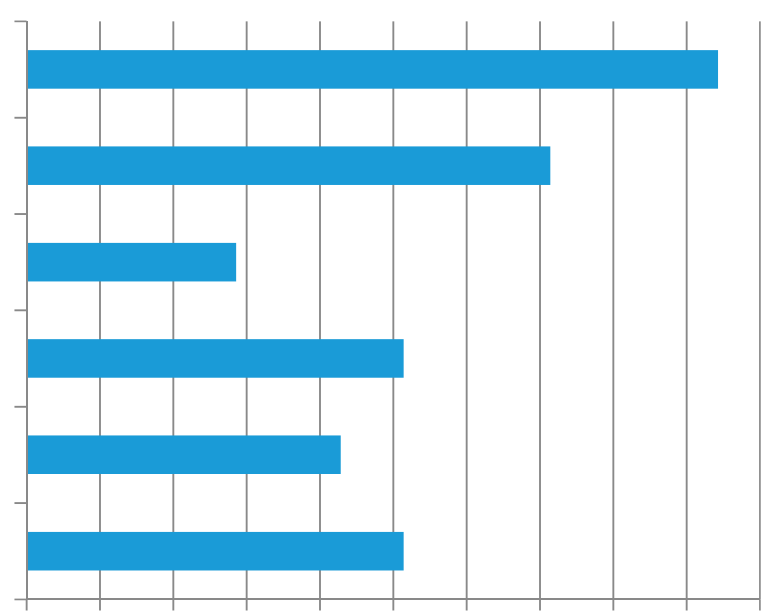

$\begin{array}{lllllllllll}0 & 0.1 & 0.2 & 0.3 & 0.4 & 0.5 & 0.6 & 0.7 & 0.8 & 0.9 & 1\end{array}$

Figure 5. Challenges towards consulting Energy Service Companies (ESCOs) by the respondents.

\section{Discussion}

The results depict that the most significant barriers to energy efficiency in non-energy-intensive manufacturing companies in Bangladesh were "Inadequate capital expenditure" and "Other preferences for capital venture", followed by "Time limitation or other significant work", "Inadequate support from preeminent administration", "Unpredictability nature of energy parameters (prices, slow rate of return)", and "Inadequate financial policy". Relating our findings to low energy-intensive industries in Sweden, the top rated barriers to energy efficiency were "cost of production disruption or hassle", "inadequate time or other prioritized work", "information acquiring cost related to energy consumption of purchased equipment", and "technical risk due to deviation from usual technology" [5]. Relating to our findings, the most significant barriers to small and medium-sized enterprises (SMEs) in Australia are generally financial based, including the fact of staff engagement at energy management schemes and alternative options for capital investment [42]. "Lack of information about energy efficient measures", "Lack of time to analyse energy efficiency potentials", "Other investment priorities", "Risk of varying energy costs in future", and "Split incentives" are the most prominent barriers to energy efficiency for non-intensive firms in Germany [38].

Although a good amount of research has been done on barriers to energy efficiency, little research has been done on driving forces to overcoming these barriers [43]. Groot et al. first contributed to finding drivers by analysing Dutch manufacturing enterprises, through which he identified minimization of expenditure due to lower energy use and financial subsidies as the top-ranked driving forces for energy efficiency [44]. Another study conducted by Cagno et al. identified "long-term energy strategy", "clarity of information", and "cost reduction from lower energy use" as significant drivers [16,45]. According to our study, the most powerful drivers for energy efficiency on low energy-intensive manufacturing companies in Bangladesh were "Owner's requirement". "Expense minimization due to lower energy consumption", "Assurance from preeminent management", "Risk of high energy prices in future", "Favorable loans for efficient energy financing", and "Agreements with tax dispensation" as the significant driving forces for efficient energy management in Bangladesh. "Long-term strategic plan", "Increasing energy prices", "People with real ambitions", and "People's authority to influence in investment decisions" were considered the major driving forces for energy efficiency in Sweden [5], although, in Bangladesh, these drivers have less of a significant effect as per the response of the respondent. In Australia, the most motivating factor or drivers were financial interest, such as reduced energy costs, potential access funding, and reducing Economic Regulation Authority (EAR) fees. Around 89\% of respondents thought that financial interest was the most dominant driver for energy efficiency in low-intensive companies in Australia [42]. A similar study in Italy showed that "Allowance or public financing", 
"External pressures", "Long term benefits", and "Access to energy efficiency experts" were considered as the most perceived drivers in low-intensive manufacturing companies [46].

Based on the result of our study, our recommendation for the policy makers of Bangladesh would be to invest in research and development at the industrial energy efficiency sector. In addition, the inclusion of medium and small-sized industrial sectors should be done in the industrial energy efficiency scheme by SREDA, as the focus has been on large industries only. The outcomes of this study could be the benchmark for fine-tuning a customized policy for different industrial sectors of Bangladesh. This research is a bit of an expansive riddle with regard to industrial energy efficiency in Bangladesh.

\section{Conclusions}

Despite significant potential, the energy management and energy efficiency practices in Bangladesh have remained an unexplored territory for quite a long period of time. Although high energy-intensive industries showed much interest in embracing the right practice, no significant studies were conducted to deal with similar problems in the context of small-scale low energy-intensive industries. A lack of adequate policies and effective pricing, as well as difficulties in attracting private investments remain in energy efficiency practices for both high and low energy-intensive industries. The goal of the study was to explore the challenges and motivations for energy management practices in the industries that are not energy intensive. The study discovered that none of the participating non-energy-intensive manufacturing industries were in affiliation with any ESCOs, and things such as lack of awareness hindered the progress toward energy efficiency. Thus, there seems to be a hidden business opportunity for ESCOs in Bangladesh, which most likely also holds for other developing countries. Future research on energy services in developing countries may thus be a great topic of interest to researchers in Bangladesh, as well as in other developing countries.

Being mostly short-term profit-oriented, it was found that low energy-intensive industries are not entirely aware of the concepts of energy management and energy efficiency. This study identified their "Inadequate capital expenditure" and "Other preferences for capital venture" were the most critical barriers. Furthermore, several risk factors due to future uncertainty, lack of financial policies, and insufficient support from top management were a few of the significant barriers towards energy management practices. Finding an optimized cost-benefit ratio may vary among industries, and such optimization demands further research. Outcomes of such studies could be practically beneficial and convince stakeholders to find and adopt the best practices for low energy-intensive industries.

In such case, the owners of non-energy-intensive industries could act as a primary driving force for energy efficiency. Attracting investments as beneficial loans, proper regulations, long-term tax exemptions are other significant driving forces that have also been identified in this study, where the government can play a pivotal role. Furthermore, the increased cost of energy and lowered tariff for lower energy use could accelerate the process of adoption. Pressure and subsidies from the government or from a third party for energy audits are also noteworthy driving forces for energy management practices in non-energy-intensive industries.

Respondents in the low-energy intensive sector strongly believe that energy management practices for efficiency should be implemented under a common framework of an energy efficiency policy. The stakeholders also believe that significant investment and fruitful policies from authorities for both implementation and awareness related to energy efficiency are required for sustainability and relevant environmental considerations. Governmental subsidies to overcome the lack of experts could significantly facilitate the journey towards energy efficiency.

Supplementary Materials: The Supplementary Materials are available online at http://www.mdpi.com/2071-1050/ 11/9/2671/s1.

Author Contributions: Conceptualization, A.S.M.M.H. and P.T.; methodology, A.S.M.M.H.; data collection, A.S.M.M.H.; formal analysis, A.S.M.M.H. and R.H.; investigation, A.S.M.M.H. and R.H.; resources, A.S.M.M.H. 
and T.H.S.; writing—original draft preparation, A.S.M.M.H.; writing-review and editing, A.S.M.M.H. and P.T.; visualization, A.S.M.M.H.; supervision, P.T.; project administration, A.S.M.M.H. and P.T.

Funding: This research project did not receive any external funding.

Conflicts of Interest: The authors declare no conflict of interest.

\section{References}

1. Finance Division, Ministry of Finance-Government of the People's Republic of Bangladesh. Available online: https://mof.gov.bd/ (accessed on 15 October 2018).

2. The World Bank. TCdata360: Industrialization Intensity Index. 3 November 2017. Available online: https://tcdata360.worldbank.org/indicators/mva.ind.int?country=BGD\&indicator=3793\&viz=line_ chart\&years=1990,2014 (accessed on 3 November 2017).

3. Thollander, P.; Ottosson, M. Energy management practices in Swedish energy-intensive industries. J. Clean. Prod. 2010, 18, 1125-1133. [CrossRef]

4. Thollander, P.; Mardan, N.; Karlsson, M. Optimization as investment decision support in a Swedish medium-sized iron foundry - A move beyond traditional energy auditing. Appl. Energy 2009, 86, 433-440. [CrossRef]

5. Rohdin, P.; Thollander, P. Barriers to and driving forces for energy efficiency in the non-energy-intensive manufacturing industry in Sweden. Energy 2006, 31, 1836-1844. [CrossRef]

6. Carolina Digital Repository. Essays on Climate Change Mitigation, Building Energy Efficiency, and Urban Form. Available online: https://cdr.lib.unc.edu/record/uuid:f5bb3589-e8e6-465d-89e1-0254f6814faa. (accessed on 1 May 2019).

7. Palm, J.; Thollander, P. An interdisciplinary perspective on industrial energy efficiency. Appl. Energy 2010, 87, 3255-3261. [CrossRef]

8. Li, C.; Song, Y. Government response to climate change in China: A study of provincial and municipal plans. J. Environ. Plan. Manag. 2016, 59, 1679-1710. [CrossRef]

9. Thollander, P.; Backlund, S.; Trianni, A.; Cagno, E. Beyond barriers-A case study on driving forces for improved energy efficiency in the foundry industries in Finland, France, Germany, Italy, Poland, Spain, and Sweden. Appl. Energy 2013, 111, 636-643. [CrossRef]

10. Apeaning, R.W.; Thollander, P. Barriers to and driving forces for industrial energy efficiency improvements in African industries-A case study of Ghana's largest industrial area. J. Clean. Prod. 2013, 53, 204-213. [CrossRef]

11. Hasan, A.S.M.M.; Hoq, M.T.; Thollander, P. Energy management practices in Bangladesh's iron and steel industries. Energy Strategy Rev. 2018, 22, 230-236. [CrossRef]

12. Bangladesh Power Development Board. Available online: http://www.bpdb.gov.bd/bpdb_new/index.php/ site/page/5a3f-2fdb-e75f-3cab-e66b-f70d-5408-cbc9-f489-c31c. (accessed on 29 August 2018).

13. Bedi, H.P. 'Our energy, our rights': National extraction legacies and contested energy justice futures in Bangladesh. Energy Res. Soc. Sci. 2018, 41, 168-175. [CrossRef]

14. Technology Transfer of Energy Efficient Technologies in Industry: A Review of Trends and Policy Issues-ScienceDirect. Available online: https://www.sciencedirect.com/science/article/pii/ S0301421500000975. (accessed on 15 January 2019).

15. Islam, S.; Khan, M.Z.R. A Review of Energy Sector of Bangladesh. Energy Procedia 2017, 110, 611-618. [CrossRef]

16. Trianni, A.; Cagno, E.; Farné, S. Barriers, drivers and decision-making process for industrial energy efficiency: A broad study among manufacturing small and medium-sized enterprises. Appl. Energy 2016, 162, 1537-1551. [CrossRef]

17. Malinauskaite, J.; Jouhara, H.; Ahmad, L.; Milani, M.; Montorsi, L.; Venturelli, M. Energy efficiency in industry: EU and national policies in Italy and the UK. Energy 2019, 172, 255-269. [CrossRef]

18. Soepardi, A.; Thollander, P. Analysis of Relationships among Organizational Barriers to Energy Efficiency Improvement: A Case Study in Indonesia's Steel Industry. Sustainability 2018, 10, 216. [CrossRef]

19. Li, Y.; Chiu, Y.; Lin, T.-Y. Energy and Environmental Efficiency in Different Chinese Regions. Sustainability 2019, 11, 1216. [CrossRef] 
20. Caffal, C. Energy Management in Industry. Centre for the Analysis and Dissemination of Demonstrated Energy Technologies (CADDET). Available online: https://scholar.google.com/scholar_lookup?title=Energy \% 20management\%20in\%20industry\&author=C.\%20Caffal\&publication_year=1996 (accessed on 16 April 2019).

21. Trianni, A.; Cagno, E.; Bertolotti, M.; Thollander, P.; Andersson, E. Energy management: A practice-based assessment model. Appl. Energy 2019, 235, 1614-1636. [CrossRef]

22. Schulze, M.; Nehler, H.; Ottosson, M.; Thollander, P. Energy management in industry-A systematic review of previous findings and an integrative conceptual framework. J. Clean. Prod. 2016, 112, 3692-3708. [CrossRef]

23. Si, F.; Wang, J.; Han, Y.; Zhao, Q.; Han, P.; Li, Y. Cost-efficient multi-energy management with flexible complementarity strategy for energy internet. Appl. Energy 2018, 231, 803-815. [CrossRef]

24. Hock, K.P.; Radjabli, K.; McGuiness, D.; Boddeti, M. Predictive analysis in energy management system. In Proceedings of the 2016 IEEE 16th International Conference on Environment and Electrical Engineering (EEEIC), Florence, Italy, 7-10 June 2016; pp. 1-4.

25. Backlund, S.; Thollander, P.; Palm, J.; Ottosson, M. Extending the energy efficiency gap. Energy Policy 2012, 51, 392-396. [CrossRef]

26. Energy Management for Businesses | Guides | Carbon Trust. Available online: https://www.carbontrust.com/ resources/guides/energy-efficiency/energy-management/ (accessed on 27 December 2018).

27. Amaral, J.; Reis, C.; Brandão, R.F.M. Energy Management Systems. In Proceedings of the 2013 48th International Universities' Power Engineering Conference (UPEC), Dublin, Ireland, 7-10 June 2013; pp. 1-6.

28. Fahad, M.; Naqvi, S.A.A.; Atir, M.; Zubair, M.; Shehzad, M.M. Energy Management in a Manufacturing Industry through Layout Design. Procedia Manuf. 2017, 8, 168-174. [CrossRef]

29. Lawrence, A.; Karlsson, M.; Thollander, P. Effects of firm characteristics and energy management for improving energy efficiency in the pulp and paper industry. Energy 2018, 153, 825-835. [CrossRef]

30. Wen, Z.; Wang, Y.; Zhang, C.; Zhang, X. Uncertainty analysis of industrial energy conservation management in China's iron and steel industry. J. Environ. Manag. 2018, 225, 205-214. [CrossRef] [PubMed]

31. Power Division, Government of Bangladesh. Available online: https://powerdivision.portal.gov.bd/ (accessed on 14 October 2018).

32. Sustainable and Renewable Energy Development Authority. Available online: http://www.sreda.gov.bd/ index.php/site/page/8ea5-9078-a242-7eab-f875-fdc4-bb9f-3adf-2d15-c033 (accessed on 17 April 2019).

33. Primc, K.; Slabe-Erker, R.; Majcen, B. Constructing energy poverty profiles for an effective energy policy. Energy Policy 2019, 128, 727-734. [CrossRef]

34. Royston, S.; Selby, J.; Shove, E. Invisible energy policies: A new agenda for energy demand reduction. Energy Policy 2018, 123, 127-135. [CrossRef]

35. Yin, R.K. Case Study Research: Design and Methods; Sage Publications: Newbury Park, CA, USA, 1994.

36. Siggelkow, N. Persuasion with Case Studies. Acad. Manag. J. 2007, 50, 20-24. [CrossRef]

37. Ministry of Commerce, Government of Bangladesh. Available online: https://mincom.gov.bd/ (accessed on 1 May 2019).

38. Sorrell, S.; Mallett, A.; Nye, S. Barriers to Industrial Energy Efficiency: A Literature Review. 2011. Available online: http://www.unido.org//fileadmin/user_media/Publications/Research_and_statistics/ Branch_publications/Research_and_Policy/Files/Working_Papers/2011/WP102011\%20Barriers\%20to\% 20Industrial\%20Energy\%20Efficiency\%20-\%20A\%20Literature\%20Review.pdf (accessed on 27 January 2019).

39. Cai, W.; Liu, F.; Xie, J.; Zhou, X. An energy management approach for the mechanical manufacturing industry through developing a multi-objective energy benchmark. Energy Convers. Manag. 2017, 132, 361-371. [CrossRef]

40. Vine, E. An international survey of the energy service company (ESCO) industry. Energy Policy 2005, 33, 691-704. [CrossRef]

41. Soroye, K.L.; Nilsson, L.J. Building a business to close the efficiency gap: The Swedish ESCO Experience. Energy Effic. 2010, 3, 237-256. [CrossRef]

42. Meath, C.; Linnenluecke, M.; Griffiths, A. Barriers and motivators to the adoption of energy savings measures for small- and medium-sized enterprises (SMEs): The case of the ClimateSmart Business Cluster program. J. Clean. Prod. 2016, 112, 3597-3604. [CrossRef] 
43. Walker, B.; Redmond, J.; Sheridan, L.; Wang, C.; Goeft, U. Small and Medium Enterprises and the Environment: Barriers, Drivers, Innovation and Best Practice: A Review of the Literature; ECU Publ. Pre. 2011; Edith Cowan University: Perth, Australia, January 2008.

44. De Groot, H.L.; Verhoef, E.T.; Nijkamp, P. Energy saving by firms: Decision-making, barriers and policies. Energy Econ. 2001, 23, 717-740. [CrossRef]

45. Cagno, E.; Trianni, A.; Abeelen, C.; Worrell, E.; Miggiano, F. Barriers and drivers for energy efficiency: Different perspectives from an exploratory study in the Netherlands. Energy Convers. Manag. 2015, 102, 26-38. [CrossRef]

46. Cagno, E.; Trianni, A. Exploring drivers for energy efficiency within small- and medium-sized enterprises: First evidences from Italian manufacturing enterprises. Appl. Energy 2013, 104, 276-285. [CrossRef]

(C) 2019 by the authors. Licensee MDPI, Basel, Switzerland. This article is an open access article distributed under the terms and conditions of the Creative Commons Attribution (CC BY) license (http://creativecommons.org/licenses/by/4.0/). 